\title{
Evidence for Reduced Thermic Effect of Insulin and Glucose Infusions in Pima Indians
}

\author{
C. Bogardus, S. Lillioja, D. Mott, J. Zawadzki, A. Young, and W. Abbott \\ Phoenix Clinical Research Section, National Institute of Arthritis, Diabetes, and Digestive and Kidney Diseases, \\ National Institutes of Health, Phoenix, Arizona 85016
}

\begin{abstract}
Several authors have reported a reduced thermic effect of food in obese subjects. The hyperinsulinemic-euglycemic clamp technique has been used to measure one component of the thermic effect of food, insulin and insulin-mediated glucose disposal. We used this technique to measure the thermic responses to insulin and glucose infusions in 120 glucosetolerant Pima Indians, a population with a high prevalence of obesity. During high-dose insulin infusions $\left(400 \mathrm{mU} / \mathrm{m}^{2}\right.$ per min) the measured increase in energy expenditure (MEE), $150 \pm 6 \mathrm{cal} / \mathrm{min}$, was greater than the predicted increase in energy expenditure (PEE), $72 \pm 2 \mathrm{cal} / \mathrm{min}$, for glucose storage as glycogen. During low-dose insulin infusions $\left(40 \mathrm{mU} / \mathrm{m}^{2}\right.$ per $\mathrm{min}$ ) the mean MEE, $6 \pm 5 \mathrm{cal} / \mathrm{min}$, was not significantly different from zero and was not greater than the mean PEE, $9 \pm 1 \mathrm{cal} / \mathrm{min}$. These data were in contrast to results obtained from Caucasians by others and suggested a markedly reduced thermic effect of low-dose insulin and glucose infusions in Pima Indians. We also studied 23 glucose-tolerant male Caucasians and compared their results with the results from male Indians matched for glucose storage rates and obesity. The results showed that the thermic response to insulin and glucose infusions was similar in the two racial groups during high-dose insulin infusions but was markedly reduced in the Indians compared with the Caucasians during low-dose insulin infusions.
\end{abstract}

\section{Introduction}

Several authors have reported a reduced thermic effect of food in obese compared with lean subjects (1-3), although this has not been a universal finding (4). It has not been clear whether the abnormal thermic response is acquired or precedes the obese condition. Recently, Schutz et al. (5) reported persistence of a reduced thermic response to oral glucose in a group of obese women after weight reduction. A reduced thermic response to food may therefore precede obesity and possibly contribute to its pathogenesis in some subjects. Evaluation of the mechanisms of the thermic response may increase our understanding of the causes of obesity in some individuals.

The thermic response to food is probably comprised of several processes, including the thermic costs of digestion, absorption, and metabolism of nutrients. Recently, the hyperinsulinemic-euglycemic clamp technique has been used to measure the thermic effect of one component of this process, insulin and insulin-mediated glucose metabolism (6-8). We have used this technique to determine the thermic response to

Received for publication 10 October 1984 and in revised form 26 December 1984.

The Journal of Clinical Investigation, Inc.

Volume 75, April 1985, 1264-1269 insulin and glucose infusions in a large number of male and female Pima Indians, a population with a high prevalence of obesity (9). A subgroup of male Indians was also compared with a group of closely matched male Caucasians. The results show that there is a reduced thermic effect of low-dose insulin and glucose infusions in male Pima Indians.

\section{Methods}

Male and female Pima Indians and male Caucasians were admitted to the Phoenix Clinical Research Center (Phoenix, AZ) for study. After written informed consent was obtained, all subjects were physically examined and a 12-lead electrocardiogram recorded. After an overnight fast, blood was drawn for complete blood count, liver function tests, blood urea nitrogen, creatinine, electrolytes, calcium, total protein, and albumin. No subjects were taking medications, and all had normal physical examinations, electrocardiograms, and blood tests. The percent body fat of each volunteer was estimated by underwater weighing with correction for the simultaneously measured residual lung volume (10). After $3 \mathrm{~d}$ of a weight-maintaining diet containing at least $200 \mathrm{~g}$ carbohydrate/d, and after a 10-h overnight fast, an oral glucose tolerance test was performed (11).

Only subjects with normal glucose tolerance according to the National Diabetes Group Criteria (11) were accepted into the study. There were $\mathbf{7 6}$ male and 44 female Pima Indians studied (Table I). 23 male Caucasians were also studied. Indian males were compared with male Caucasians by matching for rates of insulin glucose-mediated storage rates (see below) and percent body fat. During the low-dose insulin infusions, matches were available for 13 Caucasians (Table III), and at the higher plasma insulin concentrations, 11 Caucasians could be matched with one Indian (Table IV).

Hyperinsulinemic-euglycemic clamp technique (Fig. 1). After the oral glucose tolerance test and after a 10-h overnight fast, an intravenous catheter was placed in an antecubital vein for infusion of insulin, glucose, and 3- $\mathrm{H}^{3}$-glucose. A primed continuous infusion of $3-\mathrm{H}^{3}$ glucose was then begun and continued for $280 \mathrm{~min}$. The $3-\mathrm{H}^{3}$-glucose was given as a $30-\mu \mathrm{Ci}$ bolus and was followed by a continuous infusion of $0.30 \mu \mathrm{Ci} / \mathrm{min}$. Another catheter was placed retrograde in a dorsal vein of the contralateral hand for blood withdrawal. The hand was kept in a warming box at $70^{\circ} \mathrm{C}$. After $250 \mathrm{~min}$, four blood samples were drawn over a 30-min period for determination of $3-\mathrm{H}^{3}$-glucose specific activity. A primed continuous $\left(40 \mathrm{mU} / \mathrm{m}^{2}\right.$ per $\left.\min \right)$ insulin infusion (Nordisk, MD) was then started and continued for $100 \mathrm{~min}$. This was followed by another primed continuous insulin infusion $(400$ $\mathrm{mU} / \mathrm{m}^{2}$ per min) for $100 \mathrm{~min}$. After the start of the initial insulin infusion, a variable infusion of $20 \%$ glucose was given to maintain the plasma glucose concentration at each subject's fasting plasma glucose concentration. Blood for plasma glucose concentration was drawn every $5 \mathrm{~min}$ throughout the test. The mean plasma insulin and glucose concentrations achieved in the Indians and Caucasians during the procedures are shown in Tables II, III, and IV.

The appearance rate $\left(R_{\mathrm{a}}\right)^{1}$ of glucose during the last $\mathbf{4 0} \mathrm{min}$ of the low-dose insulin infusion was calculated from the blood 3- $\mathrm{H}^{3}$-glucose specific activities using Steele's non-steady state equations (12). When the $R_{\mathrm{a}}$ equals the exogenous glucose infusion rate the endogenous

1. Abbreviation used in this paper: $R_{\mathrm{a}}$, appearance rate. 
Table I. Characteristics of All Pima Indian Subjects

\begin{tabular}{lcc}
\hline & & Range \\
\hline Sex $(M / F)$ & $76 / 44$ & - \\
Age $(y r)$ & $24 \pm 1 \ddagger$ & $18-41$ \\
Height $(\mathrm{cm})$ & $168.0 \pm 0.7 \ddagger$ & $149-182$ \\
Weight $(\mathrm{kg})$ & $91.8 \pm 2.4 \ddagger$ & $47.9-188.1$ \\
Body fat $(\%)^{*}$ & $32 \pm 1 \ddagger$ & $8-51$ \\
\hline
\end{tabular}

* Body fat was determined by underwater weighing. $\ddagger$ Mean \pm SEM.

glucose production rate is assumed to be completely suppressed, so that the total glucose disposal rate equals the exogenous glucose infusion rate. During the high-dose insulin infusion the endogenous glucose production rate was assumed to be completely suppressed, so that the $R_{\mathrm{a}}$ was equal to the exogenous glucose infusion rate.

Respiratory exchange measurements. $1 \mathrm{~h}$ before the start of the insulin infusions, a clear plastic, ventilated hood was placed over the subject's head. Room air was drawn through the hood, and the flow rate measured by a pneumotachograph (Gould Inc., Recording Systems Div., Cleveland, $\mathrm{OH}$ ). A constant fraction of expired air was withdrawn and analyzed for oxygen and carbon dioxide content. The oxygen analyzer was a zirconium cell analyzer and the carbon dioxide analyzer was an infrared analyzer (Applied Electrochemistry Inc., Sunnyvale, CA). The analyzers and flowmeter were connected to a desktop computer (Hewlett-Packard Co., Palo Alto, CA), which recorded continual, integrated calorimetric measurements every 5 min for the hour before and throughout the insulin infusions. The protein oxidation during the test was estimated from the urinary urea production rate. The mean nonprotein respiratory quotient, substrate oxidation rates, and energy expenditure were calculated from the equations of Lusk (13) for the $40 \mathrm{~min}$ before the insulin infusions and for the last 40 min of both the low- and high-dose insulin infusions (Fig. 1).

Data calculation and analysis. The nonoxidative glucose disposal rate, termed glucose storage rate, was calculated as the difference between the mean rate of glucose uptake and mean glucose oxidation rate during the last $\mathbf{4 0} \mathrm{min}$ of the low- and high-dose insulin infusions. The change in energy expenditure (cal/min) during both insulin infusions was calculated as the difference between the mean energy expenditure during the last $\mathbf{4 0} \mathrm{min}$ of the basal period and the energy expenditure during the last $40 \mathrm{~min}$ of both insulin infusions. The predicted rates of energy expenditure during the last $40 \mathrm{~min}$ of both insulin infusions were estimated from the theoretical cost of storing glucose as glycogen, which was based on the estimate that 2 out of 38 mol ATP theoretically available from total oxidation of glucose are required to store glucose as glycogen (14). The cost of this process was calculated by multiplying the energy content of the glucose stored $(3.75 \mathrm{kcal} / \mathrm{g})$ by $2 / 38$ or $5.3 \%$.
Table II. Hyperinsulinemic-Euglycemic Clamp Results in All 120 Indians

\begin{tabular}{lcc}
\hline & $\begin{array}{l}\text { Low-dose } \\
\text { insulin infusion* }\end{array}$ & $\begin{array}{l}\text { High-dose } \\
\text { insulin infusion* }\end{array}$ \\
\hline Plasma glucose $(\mathrm{mg} / 100 \mathrm{ml})$ & $92 \pm 1$ & $92 \pm 1$ \\
Plasma insulin $(\mu \mathrm{U} / \mathrm{ml})$ & $120 \pm 3$ & $1,859 \pm 36$ \\
Glucose uptake $(\mathrm{mg} / \mathrm{min})$ & $223 \pm 6$ & $659 \pm 13$ \\
Glucose oxidation $(\mathrm{mg} / \mathrm{min})$ & $179 \pm 4$ & $297 \pm 5$ \\
Glucose storage $(\mathrm{mg} / \mathrm{min})$ & $44 \pm 5$ & $362 \pm 10$
\end{tabular}

* Mean \pm SEM.

Plasma insulin concentrations were determined using the Herbert modification (15) of the radioimmunoassay of Yalow and Berson (16). Tritiated glucose specific activity in blood samples was determined after precipitating protein with perchloric acid as described previously (17).

All data are expressed as the mean $\pm \mathrm{SE}$ of the mean. All statistical analyses, including linear regression analyses and calculations of $95 \%$ confidence limits for predicted values, were calculated using the Statistical Analysis System, SAS Institute, Inc., Cary, NC.

\section{Results}

Indians. The Indians represented a wide range of ages, heights, weights, and percent body fats (Table I). During the low-dose insulin infusion, glucose storage was only a small portion of the total glucose uptake, but at the higher plasma insulin concentration, glucose storage was more than half of the glucose uptake (Table II). During the low-dose insulin infusions, the increase in energy expenditure predicted for the glucose storage as glycogen was $9 \pm 1 \mathrm{cal} / \mathrm{min}$. The measured increase in energy expenditure was only $6 \pm 5 \mathrm{cal} / \mathrm{min}$ and was not significantly different from zero. At the higher plasma insulin concentration, the measured increase in energy expenditure, $150 \pm 6 \mathrm{cal} / \mathrm{min}$, exceeded the predicted increase in energy expenditure of $72 \pm 2 \mathrm{cal} / \mathrm{min}$.

The relationship between the change in energy expenditure and glucose storage during both insulin infusions is shown in Fig. 2. The change in energy expenditure was plotted against glucose storage rates and not changes in glucose storage rates, because in the basal state, before insulin and glucose infusion, there is no net glucose storage. Net glucose storage occurs only with glucose infusion. During the low-dose insulin infusion, the relationship between the change in energy expenditure $(y)$ and glucose storage $(x)$, with $y=0.07 x$, was not significantly

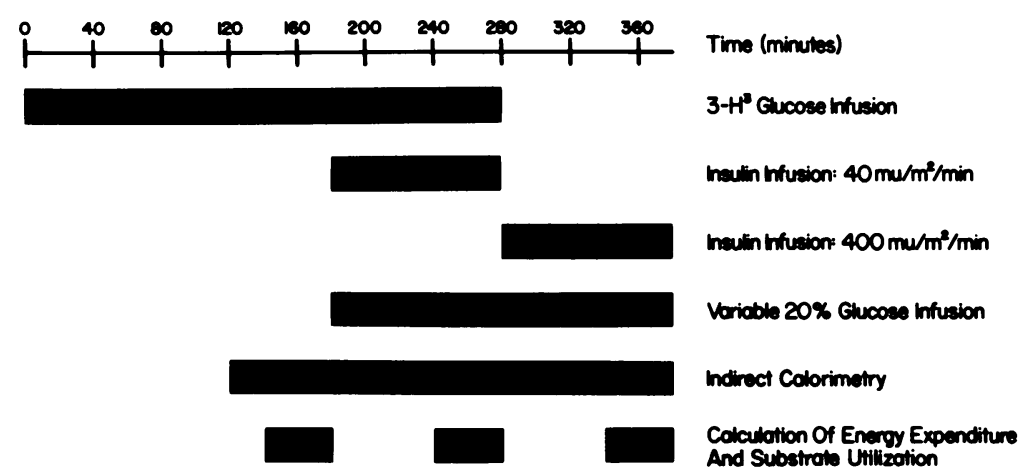

Figure 1. Experimental protocol. 
Table III. Comparison of Subset of Male Indians and Caucasians: Subject Characteristics and Results of Lower Insulin Dose Hyperinsulinemic-Euglycemic Clamp Procedure

\begin{tabular}{|c|c|c|c|}
\hline & Caucasians & Indians & $P$ value \\
\hline$n$ & 13 & 13 & - \\
\hline Age $(y r)$ & $25 \pm 1$ & $22 \pm 1$ & $<0.05$ \\
\hline Height $(\mathrm{cm})$ & $177.5 \pm 1.6$ & $173.9 \pm 1.1$ & NS \\
\hline Weight $(k g)$ & $79.4 \pm 4.7$ & $73.8 \pm 4.6$ & NS \\
\hline Body fat (\%) & $18 \pm 2$ & $18 \pm 2$ & NS \\
\hline \multicolumn{4}{|l|}{ Clamp results } \\
\hline Glucose $(\mathrm{mg} / 100 \mathrm{ml})$ & $88 \pm 1$ & $90 \pm 1$ & $<0.05$ \\
\hline Insulin $(\mu U / m l)$ & $114 \pm 5$ & $104 \pm 5$ & NS \\
\hline $\begin{array}{l}\text { Glucose uptake } \\
(\mathrm{mg} / \mathrm{min})\end{array}$ & $281 \pm 14$ & $282 \pm 19$ & NS \\
\hline $\begin{array}{l}\text { Glucose oxidation } \\
(\mathrm{mg} / \mathrm{min})\end{array}$ & $189 \pm 15$ & $188 \pm 12$ & NS \\
\hline $\begin{array}{l}\text { Glucose storage } \\
(\mathrm{mg} / \mathrm{min})\end{array}$ & $93 \pm 20$ & $95 \pm 17$ & NS \\
\hline
\end{tabular}

different from the relationship between the predicted change in energy expenditure for storing glucose as glycogen ( $y$ $=0.20 x$ ). The slope and intercept of the relationship were also not significantly different from zero. During the high-dose insulin infusions, the linear regression of the measured changes in energy expenditure versus glucose storage was $y=0.22 x$ +72 . The intercept but not the slope was significantly different from the predicted change in energy expenditure $(P<0.0001)$. Thus, at the low plasma insulin concentration, there was no difference between the measured and predicted increase in energy expenditure. At the higher dose plasma insulin concentration, there was a constant increase in measured energy expenditure, above that predicted for glucose storage as glycogen, at all glucose storage rates.

There was no significant correlation between the change in energy expenditure during the low- or high-dose insulin

Table IV. Comparison of Subset of Male Indians and Caucasians: Subject Characteristics and Results of Higher Insulin Dose Hyperinsulinemic-Euglycemic Clamp Procedure

\begin{tabular}{|c|c|c|c|}
\hline & Caucasians & Indians & $P$ value \\
\hline$n$ & 11 & 11 & - \\
\hline Age $(y r)$ & $25 \pm 2$ & $24 \pm 2$ & NS \\
\hline Height $(\mathrm{cm})$ & $176.0 \pm 1.5$ & $174 \pm 1.4$ & NS \\
\hline Weight $(k g)$ & $78.6 \pm 5.7$ & $72.2 \pm 4.7$ & NS \\
\hline Body fat (\%) & $19 \pm 2$ & $19 \pm 2$ & NS \\
\hline \multicolumn{4}{|l|}{ Clamp results } \\
\hline Glucose $(\mathrm{mg} / 100 \mathrm{ml})$ & $90 \pm 1$ & $90 \pm 1$ & NS \\
\hline Insulin $(\mu U / m l)$ & $2,003 \pm 112$ & $1,632 \pm 76$ & $<0.02$ \\
\hline $\begin{array}{l}\text { Glucose uptake } \\
(\mathrm{mg} / \mathrm{min})\end{array}$ & $735 \pm 17$ & $736 \pm 25$ & NS \\
\hline $\begin{array}{l}\text { Glucose oxidation } \\
(\mathrm{mg} / \mathrm{min})\end{array}$ & $322 \pm 20$ & $323 \pm 14$ & NS \\
\hline $\begin{array}{l}\text { Glucose storage } \\
(\mathrm{mg} / \mathrm{min})\end{array}$ & $413 \pm 18$ & $413 \pm 19$ & NS \\
\hline
\end{tabular}

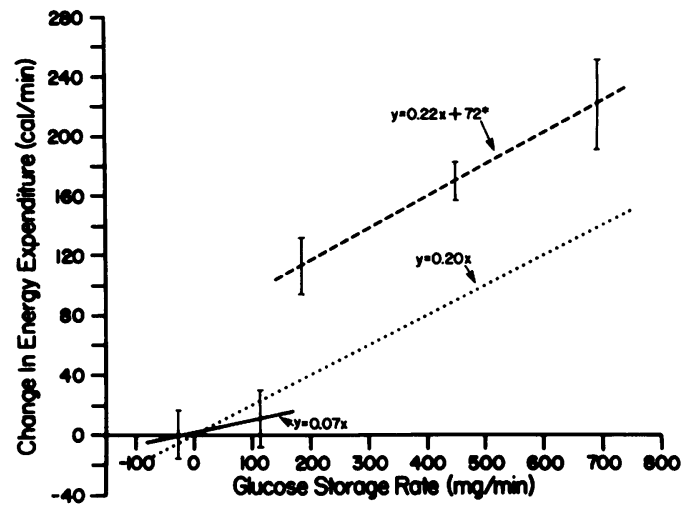

Figure 2. Relationships between measured increases in energy expenditure and glucose storage rates during the low-dose (solid line) and high-dose (dashed line) insulin euglycemic clamp procedure. The dotted line represents the increases in energy expenditure predicted for glucose storage as glycogen. 95\% confidence limits are shown for two predicted values of changes in energy expenditure during the low-dose insulin infusion and for three values during the high-dose insulin infusions. (*), intercept of this relationship significantly different $(P<0.0001)$ from the intercept of the relationship between glucose storage and predicted increases in energy expenditure.

infusion and the degree of obesity in the Indians. There also were no differences in the changes in energy expenditure comparing male and female Indians.

Indian-Caucasian comparison. 23 Caucasians were studied, and a Caucasian was pair-matched with an Indian where possible by closely matching glucose storage rates and degrees of obesity.

During the low-dose insulin infusion, it was possible to match 13 Caucasians with 13 Indians. The groups were comparable in all study parameters except that the Indians were slightly younger and the mean plasma glucose concentration during the hyperinsulinemic-euglycemic clamp was $90 \pm 1$ $\mathrm{mg} / 100 \mathrm{ml}$, compared with $88 \pm 1 \mathrm{mg} / 100 \mathrm{ml}$ in the Caucasians (Table III). Since the glucose storage rates were similar, so were the predicted increases in energy expenditure during the clamp (Fig. 3). In the Caucasians, the measured change in
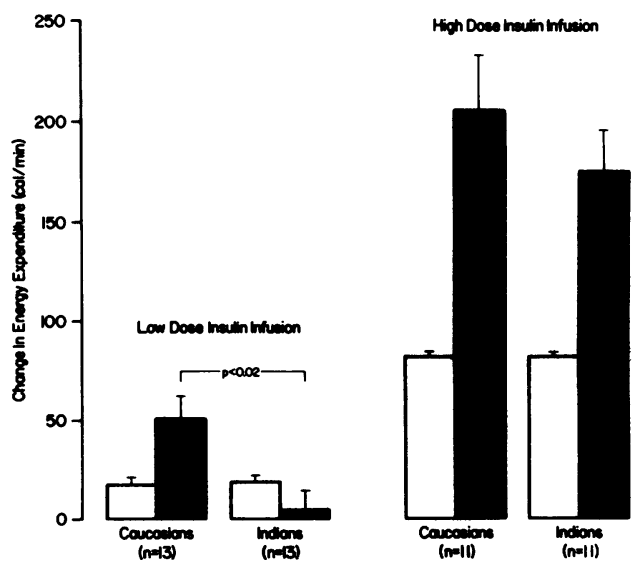

Figure 3. Predicted increases in energy expenditure for glucose storage as glycogen (open bars) and measured increases in energy expenditure (solid bars) during the low- and high-dose insulin infusions in male Indians and Caucasians. 
energy expenditure was greater than that predicted for glucose storage as glycogen. In contrast, there was no increase in energy expenditure above that predicted for glycogenesis in the Indians. The measured change in energy expenditure was significantly different between the groups $(P<0.03)$ (Fig. 3).

At the high plasma insulin concentration, matches were possible for 11 Caucasians and Indians. These groups were comparable in all study parameters except that the mean plasma insulin concentration achieved during the hyperinsulinemic-euglycemic clamp was lower in the Indians (Table IV). The reason(s) for this difference is not known, and it is quite surprising since insulin was infused at $400 \mathrm{mU} / \mathrm{m}^{2}$ per min in all subjects. There were no significant differences between the groups in predicted or measured changes in energy expenditure (Fig. 3).

\section{Discussion}

The thermic effect of food, previously defined as "specific dynamic action," has been reported as reduced or normal in obese subjects compared with lean controls (1-5). These contradictory data may be a result of different methods. It is also possible that there is a defect in the thermogenic response to food in some obese subjects and not others. In those with the defect, it has not been clear whether it precedes or is acquired with the obese condition. Schutz et al. (5) recently reported a group of obese women with reduced thermogenic responses to oral glucose. After weight loss, the defects persisted, suggesting that the abnormal thermic responses were not a result of the obesity but preceded its onset and possibly contributed to its pathogenesis.

It is therefore important to determine the mechanisms of the thermic response to food in humans, since it may increase our knowledge of the causes of obesity. There are several possible components of the thermic response to food, including the energy costs of digestion and absorption and metabolism of nutrients. Nutrient supply may also stimulate the release of thermogenic hormones that have other thermic effects. Recently, the hyperinsulinemic-euglycemic clamp technique has been used to measure the thermic effect of insulin and insulinmediated glucose metabolism (6-8).

This technique was used in this study to determine the thermic response to insulin and glucose infusions in Pima Indians, a population with a high prevalence of obesity (9). In a large group of glucose-tolerant Indians there was no increase in energy expenditure in response to insulin and glucose infusion at low plasma insulin concentrations. This was in sharp contrast to previously reported data in nondiabetic Caucasians (6-8). At very high plasma insulin concentrations an increase in energy expenditure as previously described in Caucasians (6), above that predicted for glucose storage as glycogen, was observed in the Indians.

Flatt calculated the energic cost of storing glucose as glycogen based on known rates of ATP production and use during glucose oxidation and during glucose conversion to glycogen (14). We used his calculations to estimate the predicted energic cost of glucose storage during the insulin and glucose infusions, although their accuracy was not tested under the in vivo conditions of our experiments. In this study the slope of the relationship between the measured changes in energy expenditure and glucose storage rates during both insulin infusions was not significantly different from the slope of the relationship between glucose storage rates and change in energy expenditure as predicted by Flatt's calculations. Thus, the data suggest that his calculations apply under our experimental conditions, and that part of the change in energy expenditure during glucose and insulin infusions is a result of the thermic cost of storing glucose as glycogen. At the high plasma insulin concentration there also was a constant increase in energy expenditure above that predicted for glycogenesis $(72 \mathrm{cal} / \mathrm{min}$ ), indicating an increase in energy expenditure that was independent of insulin-mediated glucose storage. This may be due to other effects of insulin (see below).

The absence of an increase in energy expenditure during the low-dose insulin infusions in the Indians was quite different from previously published data on Caucasians and may have been due to differences in methods between our laboratory and others. Also, the rates of insulin-mediated glucose disposal were lower in these Indians than previously reported in Caucasians (6). The Indians' abnormal thermic response to insulin may be characteristic of subjects with reduced insulin action rather than of Pima Indians per se. The Pima Indians studied were also more obese than some previously studied Caucasians. If a reduced thermic response to insulin was acquired with obesity rather than being an inherited characteristic, then the thermic defect observed in the Indians studied may have been a reflection of their obesity rather than of a trait that predisposes to obesity.

To eliminate the possibility that differences in degree of obesity or glucose storage rates were the explanation for the difference between our report on Indians and the reports of others on Caucasians, we compared results obtained from Caucasians and Indians who were pair-matched for glucose storage rates and degree of obesity. This was also done to consider the hypothesis that there is a constitutional thermogenic defect in the Pima Indian population with a high prevalence of obesity. During the low-dose insulin infusions, we observed the expected increased energy expenditure, above that predicted for storage in the Caucasians. In the Indians there was no increase in energy expenditure during this lowdose insulin infusion, and the results from the two groups were significantly different. During the high-dose insulin infusions, the increased energy expenditure, above that predicted for storage, was observed in both groups. There was no significant difference between the groups.

The Indian-Caucasian comparisons show that there are reduced thermic responses in the Indians during low, but not during higher dose insulin and glucose infusions. It is tempting to speculate that these reduced thermic responses contribute to the pathogenesis of obesity in this population. The thermic response to insulin and glucose infusion probably contributes predominantly to an individual's thermic response to a meal rather than to rates of basal energy expenditure or to rates of energy expenditure during exercise. The thermic effect of food accounts for $\sim 10 \%$ of the 24-h energy expenditure (18). Assuming a daily energy expenditure of 2,500-3,000 kcal, an absent thermic response to insulin and glucose infusions could therefore account for a deficit in energy expenditure of 250$300 \mathrm{kcal} / \mathrm{d}$, at most.

However, the thermic response to a meal is the result of more processes than just the response to insulin and glucose. Thus, the actual deficit in daily energy expenditure resulting 
from a defect in the thermic response to insulin and glucose is likely to be $<250-300 \mathrm{kcal} / \mathrm{d}$, perhaps as low as $125-150$ $\mathrm{kcal} / \mathrm{d}$. Over a year, or longer, a daily deficit in energy expenditure in this range could contribute significantly to causes of positive energy balance and progressive increases in body fat mass if the other components of the daily energy expenditure were unchanged. Furthermore, a reduced thermic response to insulin and glucose infusions may be an indication of a more general defect in thermic responses to a variety of stimuli.

However, it is possible that thermic responses to food, or insulin and glucose infusions, are inherited characteristics, unrelated to obesity. In fact, there was no correlation between degree of obesity and thermic responses to insulin and glucose infusions in the Indians. Nonetheless, obesity is more prevalent in Pima Indians than in Caucasians, and our Caucasian-Indian comparisons are consistent with the hypothesis that reduced thermic responses to insulin and glucose infusion predispose to obesity. These results underline the need to further clarify the mechanisms of the thermic response to insulin and glucose infusions.

There are several possible mechanisms of the thermic response to insulin and glucose infusion, including net lipogenesis, increased protein turnover (19), sodium pumping (20, 21 ), substrate cycling (22), activation of the sympathetic nervous system, or some combination of these. Net lipogenesis is unlikely to be a significant component of the increased energy expenditure. We calculated the predicted rate of glucose storage as glucose to glycogen and also as both glucose to glycogen and glucose to lipid. The predicted energy expenditures were not statistically different after comparing both methods of calculation in all three study groups, indicating that lipogenesis made no significant addition to the predicted increase in thermogenesis. The possible contribution of protein turnover, or other substrate cycling, to the thermic response to insulin has not been determined. There is new data that the sodium pump is activated by insulin in humans, and that the response is reduced in obese compared with lean subjects (Mott, D. M., R. L. Clark, W. J. Andrews, and J. E. Foley, manuscript submitted for publication). The contribution of the sodium pump to the total thermic response to insulin is unknown, however. It is also not known whether insulin activation of the sodium pump is different in Indians and Caucasians.

There is good evidence that insulin and glucose infusions are associated with activation of the sympathetic nervous system in humans. Rowe et al. (23) and Ravussin et al. (8) have shown that insulin and glucose infusions are associated with increased plasma norepinephrine concentrations. Acheson et al. (24) have recently demonstrated that the increase in energy expenditure above that predicted for glucose storage as glycogen can be almost completely eliminated by infusion of the beta-blocking agent propranolol. Thus, the absent increase in energy expenditure in the Indians in this study may be a result of a diminished activation of the sympathetic nervous system. However, the increases in energy expenditure observed during insulin and glucose infusions are probably a balance of insulin-induced increases in thermogenesis and insulin-induced reductions in thermogenesis. For example, as previously demonstrated in noninsulin-dependent diabetics (8), insulin infusions probably inhibit gluconeogenesis, and this would be associated with reduced energy expenditure. The absent increase in energy expenditure in Indians, at low plasma insulin concentration, may therefore be a result of either reduced insulininduced increases in thermogenesis or greater reductions in thermogenesis, such as occur with inhibiting gluconeogenesis or a combination of both mechanisms.

In conclusion, this study has demonstrated a reduced thermic effect of low-dose insulin and glucose infusions in Pima Indians. The hypothesis that this thermogenic defect contributes to the pathogenesis of obesity in this population warrants further study.

\section{Acknowledgments}

We thank Ms. Robinson, R.N., and the nursing staff for their assistance in performing these studies and their professional care of the volunteers while in our research ward. We also thank Karen Stone, Suzzane Moser, Deborah Wolf-Lopez, and Harlan Osife for their technical assistance, and Verna Kuwanhoyioma for secretarial assistance. Most of all, we thank the volunteers.

\section{References}

1. Pittet, P., P. Chappuis, K. Acheson, F. de Techtermann, and E. Jéquier. 1976. Thermic effect of glucose in obese subjects studied by direct and indirect calorimetry. Br. J. Nutr. 35:281-292.

2. Kyrlan, M. L., and G. A. Leveille. 1976. Calorigenic response in obese and non obese women. Am. J. Clin. Nutr. 29:1108-1113.

3. Shetty, P. S., T. R. Jung, W. P. T. James, M. A. Barrand, and B. A. Cunningham. 1981. Postprandial thermogenesis in obesity. Clin. Sci. (Oxf.). 60:519-525.

4. Welle, S. L., and R. G. Campbell. 1983. Normal thermic effect of glucose in obese women. Am. J. Clin. Nutr. 37:87-92.

5. Schutz, Y., A. Golay, J. Felber, and E. Jéquier. 1984. Decreased glucose-induced thermogenesis after weight loss in obese subjects: a predisposing factor for relapse of obesity. Am. J. Clin. Nutr. 39:380387.

6. Thiebaud, D., Y. Schutz, K. Acheson, E. Jacot, R. A. DeFronzo, J. P. Felber, and E. Jéquier. 1983. Energy cost of glucose storage in man during glucose/insulin infusions. Am. J. Physiol. 244:E216-E221.

7. Ravussin, E., and C. Bogardus. 1982. Thermogenic response to insulin and glucose infusion. A model to evaluate the different components of the thermic effect of carbohydrate. Life Sci. 31:2011-2018.

8. Ravussin, E., C. Bogardus, R. S. Schwartz, D. C. Robbins, R. R. Wolfe, E. S. Horton, E. Danforth, Jr., and E. A. H. Sims. 1983. Thermic effect of infused glucose and insulin in man. Decreased response with increased insulin resistance in obesity and noninsulindependent diabetes mellitus. J. Clin. Invest. 72:893-902.

9. Knowler, W. C., D. J. Pettitt, P. J. Savage, and P. H. Bennett. 1981. Diabetes incidence in Pima Indians: contributions of obesity and parental diabetics. Am. J. Epidemiol. 113:144-156.

10. Goldman, R. F., and E. R. Buskirk. 1961. A method for underwater weighing and the determination of body density. In Techniques for Measuring Body Composition. J. Brozek and A. Herschel, editors.

11. National Diabetes Data Group. 1979. Classification and diagnosis of diabetes mellitus and other categories of glucose intolerance. Diabetes. 28:1039-1057.

12. Steele, R. 1959. Influences of glucose loading and of injected insulin on hepatic glucose output. Ann. N.Y. Acad. Sci. 82:420-430.

13. Lusk, G. 1924. Animal calorimetry. Analysis of oxidation of mixtures of carbohydrate and fat. J. Biol. Chem. 59:41-42.

14. Flatt, J. P. 1978. The biochemistry of energy expenditure. In Recent Advances in Obesity Research. Vol. II. G. A. Bray, editor. Newman Publishing, London. 211-228.

15. Herbert, V., K. Lau, C. W. Gotlieb, and S. J. Bleicher. 1965. 
Coated charcoal immunoassay of insulin. J. Clin. Endocrinol. Metab. 25:1375-1384.

16. Yalow, R. S., and S. A. Berson. 1960. Immunoassay of endogenous plasma insulin in man. J. Clin. Invest. 39:1157-1167.

17. Best, J. D., R. G. Judzewitsch, M. A. Pfeifer, J. C. Beard, J. B. Halter, and D. Porte, Jr. 1982. The effect of chronic sulfonylurea therapy on hepatic glucose production in non-insulin dependent diabetes. Diabetes. 31:333-338.

18. Schutz, Y., T. Bessard, and E. Jéquier. 1984. Diet-induced thermogenesis measured over a whole day in obese and nonobese women. Am. J. Clin. Nutr. 40:542-552.

19. Miller, B. G., W. R. Otto, R. F. Grimble, D. A. York, and T. G. Taylor. 1979. The relationship between protein turnover and energy balance in lean and genetically obese (ob/ob) mice. Br. J. Nutr. 42:185-199.
20. Guernsy, D. C., and D. D. Stevens. 1977. The cell membrane sodium pump as a mechanism for increasing thermogenesis during cold acclimation in rats. Sciences (N.Y.). 196:908-910.

21. Bray, G. A., and D. A. York. 1979. Hypothalamic and genetic obesity in experimental animals: an autonomic and endocrine hypothesis. Physiol. Rev. 59:719-809.

22. Newsholme, E. A., and B. Crabtree. 1976. Substrate cycling in metabolic regulation and in heat generation. Biochem. Soc. Symp. 41: 61-109.

23. Rowe, J. W., J. B. Young, K. L. Minaker, A. L. Stevens, J. Pallotta, and L. Landsberg. 1981. Effect of insulin and glucose infusions on sympathetic nervous system activity in normal man. Diabetes. 30: 219-225.

24. Acheson, K., E. Jéquier, and J. Wahren. 1983. Influence of $\beta$ adrenergic blockade on glucose-induced thermogenesis in man. J. Clin. Invest. 72:981-986. 